\title{
Factors Influencing Safety Climate in the Construction Industry: A Review
}

\author{
Ibrahim Mosly \\ Civil Engineering Department, College of Engineering - Rabigh Branch, King Abdulaziz University, Jeddah, Saudi Arabia
}

\begin{abstract}
The construction industry represents a significant share of the economy for any country. Nevertheless, it is considered a dangerous industry, where the level of injuries and deaths is generally high compared to other industries. As a result, it becomes important to maintain adequate levels of safety performance on construction sites, and this can be promoted by raising the safety climate amongst the construction industry personnel. This research study aimed to identifying the factors influencing the safety climate in the construction industry. A literature review was the main method of data collection, and only journals included on the Web of Science platform were considered in the process of identifying key factors. As a result, 18 factors were identified and grouped into management related safety climate factors, and worker-related safety climate factors. In conclusion, it was found that the organization's management team had the greatest influence on safety climate; thus, they are considered accountable for safety measures as a result.
\end{abstract}

Keywords Construction industry, Safety climate, Factors

\section{Introduction}

The construction industry plays a vital part in the economy of nations worldwide. In most countries, it is considered one of the key economic pillars [1]. As the construction industry booms with a constant rise in production, the rate of accidents and deaths have also continued to increase [2]. Thus, the relationship between construction projects and safety risks and hazards demonstrates a positive correlational relationship, as it is considered to be amongst the most dangerous industries worldwide [2,3]. Hence, practices that prevent the industry-related dangers are mainly promoted by law, by people, by the related economic cost of accidents, and by administrative surveillance [3]. The presence of safety practices, procedures, and guidelines becomes an essential element for the survival and wellbeing of construction industry personnel. Furthermore, the development of health and safety principles from an organizational perspective is a significant subject of international concern [4]. Thus, both regulating authorities and organizations should prioritize the perception of safety and verify its thorough implementation on construction sites.

At construction sites, employees' play a significant role

* Corresponding author:

ikmosly@kau.edu.sa (Ibrahim Mosly)

Published online at http://journal.sapub.org/ijcem

Copyright $\odot 2019$ The Author(s). Published by Scientific \& Academic Publishing This work is licensed under the Creative Commons Attribution International License (CC BY). http://creativecommons.org/licenses/by/4.0/ when it comes to their own and others' safety. Their safety awareness can be increased and their unsafe actions can be reduced by a positive safety climate [5]. Safety climate is linked to workers' perceptions of safety rules, procedures, and practices as conveyed by the management, co-workers, and supervisors in an organization [6]. Thus, all construction organization stakeholders must have a unified safety goal. A lot of attention has been focused on safety climate, as it reveals the factual significance of safety in an organization [7]. Safety climate is a practical diagnostic tool, as it can facilitate the recognition problems that might be seen vital to improving safety [3]. Measuring the safety climate on worksites should be encouraged by employers, to recognize and resolve organizational and management problems of safety before the occurrence of safety accidents [8]. Accordingly, safety climate is linked to safety performance. In fact, safety climate can predict the levels of safety performance $[9,10]$, and safety climate and safety performance share a positive relationship [11]. An organizations' safety performance can be improved by encouraging a progressive safety climate and evolving training programs to enhance staff psychological health [9]. Securing reliable crucial factors that cover the safety climate is vital in enabling the evaluation of safety climate, which supports the recognition of effective methods to enhance safety performance [5]. Eventually, high safety climate levels in a company could result in employees perceiving that maintaining good safety practices is encouraged, in spite of increased production pressure; thus, they will behave safely [12]. 


\section{Safety Climate Research in the Construction Industry Worldwide}

To recognize the influencing safety climate factors in the construction industry, it is important to review research carried out in different countries worldwide. In general, research on safety climate and psychological strains on safety performance are limited [13]. In fact, a research gap exists in the literature of safety climate dimensions, from 2014 to present [14]. Nevertheless, a number of research studies on safety climate were reviewed, and the majority did address the important factors that influence safety climate. For instance, in a research study that examined safety in the Chinese construction industry, it was shown that the most effective stimulator of safety climate factors was constituting safety regulations and rules, together with the provision of more safety training and promotions [5]. In another study carried out in New Zealand, research investigated the methods by which main safety climate factors and individual factors affect construction workers safety behaviour [15]. Results revealed that there is a major relationship between the safety commitment of management, social support, and production pressure [15]. As a significant factor, production pressure has a direct and major effect on all safety aspects [15], as was the influence of social support on safety behaviour (although the effect on safety participation was excluded as it was found to be insignificant) [15]. Furthermore, factors including safety knowledge and safety motivation were found to have a direct effect on safety participation [15]. A research study from Ontario, Canada, exploring a specific part of safety climate illustrated that safety climate affects construction labourers safety performance as well as their psychological stress [9]. Further, in South Africa, a research study investigated the features of safety climate that exist among construction personnel and its influence on safety performance [16]. It concluded that relationships are the most important factor contributing mainly to safety performance through adequate procedures, training, and constructive communication [16]. Furthermore, a research study that examined the variances in safety climate perceptions between job positions in North America revealed that differences exist according to job position [17]. Results showed that the highest safety climate score came from project managers, followed by supervisors, then technical support employees and supervisors, and finally labourers [17]. Moreover, a research study undertaken in Hong Kong suggested that safety climate could be implemented as a significant investigative tool for assessing and enhancing site safety for construction sites [18]. It concluded that measuring safety climate could evaluate the way safety is functions on a construction site, and may therefore warn management of potential safety system failures [18]. Another study conducted in Hong Kong targeted the perception of ethnic minorities in the construction industry, and identified three safety climate factors, as follows: 1) safety resources, management commitment, and communication; 2) employee's participation and worker college influence; and 3) view of safety rules, procedures, and risks [11]. The study also demonstrated that workers' perceptions of safety climate varied greatly, depending on citizenship, marital status, dependents, and alcohol consumption [11]. Furthermore, the succeeding part of the study showed that safety climate is clearly linked to safety behaviours, which includes safety involvement and safety compliance [19]. Furthermore, it was found that safety behaviours were adversely linked to "close calls" and injuries for ethnic minority construction labourers [19]. Consequently, safety compliance and safety involvement of ethnic minority construction labourers can be enhanced by a more positive safety climate [19]. A research study carried out on the Colombian construction industry demonstrated better safety climate scores for managers compared to supervisors and labourers [20]. From the previous safety climate studies results it can be seen that safety climate can vary from one country to another, due to a wide range of issues. Furthermore, it is essential to perform research to identify the influencing factors for safety performance, and to examine the effects of safety climate on construction project safety [18]. Therefore, this research will aim to examine the factors influencing safety climate in the construction industry and to identify them in a holistic matter.

\section{Research Methodology}

Literature review forms the basis of this research and is the main source of data. The search for literature was carried out through the Saudi digital library (SDL), which provided access to many of the reputational academic databases. The main keywords used during the search included 1) Factors, 2) Safety climate, and 3) Construction. All journal articles that included clear representation of safety climate factors and was included in the Web of Science platform where considered in the safety climate factors identification process. The main objective of the literature review process was to examine previous research conducted in relation to this topic, as well as to identify the safety climate factors recognized by other researchers from different countries. The question investigated in this research was, "What are the influencing safety climate factors in the construction industry?" The answer to this research question provided the main contribution to knowledge in the form of a comprehensive list of safety climate factors in the construction industry collected from various high-quality research studies.

\section{Results and Discussion}

In total, 28 articles from 10 journals were referenced for the identification of the factors influencing safety climate in the construction industry (see Table 1). As previously mentioned in the research methodology section, only journal 
articles that were included on the Web of Science platform where considered for this process. This was made to ensure the production of a sound and inclusive list of factors influencing safety climate in the construction industry. Due to the relevance of the topic of two journals (Safety Science, and Journal of Construction Engineering and Management), these contained the greatest number of articles referenced in the factors identification process.

Table 1. Distribution of selected journal articles

\begin{tabular}{|l|c|}
\hline \multicolumn{1}{|c|}{ Journal } & $\begin{array}{c}\text { Number of } \\
\text { sources }\end{array}$ \\
\hline Safety Science (Web of Science) & 9 \\
\hline $\begin{array}{l}\text { Journal of Construction Engineering and Management } \\
\text { (Web of Science) }\end{array}$ & 7 \\
\hline Accident Analysis and Prevention (Web of Science) & 3 \\
\hline $\begin{array}{l}\text { International Journal of environmental Research and } \\
\text { Public Health (Web of Science) }\end{array}$ & 2 \\
\hline Journal of Safety research (Web of Science) & 2 \\
\hline $\begin{array}{l}\text { American Journal of Industrial Medicine (Web of } \\
\text { Science) }\end{array}$ & 1 \\
\hline Construction Economics and Building (Web of Science) & 1 \\
\hline Safety (Web of Science) & 1 \\
\hline Acta Structilia (Web of Science) & 1 \\
\hline China Information (Web of Science) & 28 \\
\hline \multicolumn{1}{|c|}{ Total } & 1 \\
\hline
\end{tabular}

Table 2. Factors influencing safety climate in the construction industry

\begin{tabular}{|c|c|c|}
\hline Safety climate factor & Source & $\begin{array}{c}\text { Number of } \\
\text { sources }\end{array}$ \\
\hline $\begin{array}{l}\text { Management } \\
\text { commitment to safety }\end{array}$ & $\begin{array}{l}{[1,4,5,7,8,11,14,15,18} \\
19,21-30]\end{array}$ & 20 \\
\hline $\begin{array}{l}\text { Safety rules, and } \\
\text { procedures }\end{array}$ & $\begin{array}{l}{[5,7,8,11,14,18,21-25,} \\
27,29-31]\end{array}$ & 15 \\
\hline Communication & $\begin{array}{l}{[1-3,11,13,14,16,19,21} \\
22,24,28,29,31]\end{array}$ & 14 \\
\hline $\begin{array}{l}\text { Supervision and } \\
\text { guidance }\end{array}$ & $\begin{array}{l}{[2,5,8,14,17,21-24,26,} \\
27,29,30]\end{array}$ & 13 \\
\hline Education and training & {$[3-5,9,14-16,22-24,30]$} & 11 \\
\hline Workers' involvement & $\begin{array}{l}{[7,14,15,18,19,21,} \\
23-26,29]\end{array}$ & 11 \\
\hline $\begin{array}{l}\text { Worker's college } \\
\text { influence }\end{array}$ & $\begin{array}{l}{[1,2,5,11,19,23,25,26,} \\
31]\end{array}$ & 9 \\
\hline $\begin{array}{l}\text { Work pressure and } \\
\text { intensity }\end{array}$ & {$[2,8,14,15,21,29,31]$} & 7 \\
\hline $\begin{array}{l}\text { Worker's attitude } \\
\text { toward health and safety }\end{array}$ & {$[1,5,7,13,19,25,26]$} & 7 \\
\hline Safety resources & {$[11,19,23,28,30,31]$} & 6 \\
\hline Supportive environment & {$[1,15,21,26,29,30]$} & 6 \\
\hline $\begin{array}{l}\text { Appraisal of risk and } \\
\text { hazard }\end{array}$ & {$[14,21,23,28,29]$} & 5 \\
\hline Competence & {$[1,21,23,29]$} & 4 \\
\hline $\begin{array}{l}\text { Safety value and reward } \\
\text { system }\end{array}$ & {$[2,27]$} & 2 \\
\hline $\begin{array}{l}\text { Management safety } \\
\text { justice }\end{array}$ & {$[1,28]$} & 2 \\
\hline
\end{tabular}

\begin{tabular}{|l|l|c|}
\hline $\begin{array}{l}\text { Workers' commitment } \\
\text { to safety }\end{array}$ & {$[15,28]$} & 2 \\
\hline Adequacy of procedures & {$[16,31]$} & 2 \\
\hline $\begin{array}{l}\text { Social security and } \\
\text { health insurance }\end{array}$ & {$[2]$} & 1 \\
\hline
\end{tabular}

The literature review process resulted in the identification of 18 safety climate factors within the construction industry (see Table 2). Different research studies identified different sets of safety climate factors. Many variables contributed to these differences, including culture, workers background, and country safety regulations and policies. Some studies identified the same safety climate factor, but with a different name, such as safety instructions against safety roles, and procedures. Thus, all safety climate factors were collated and refined in a single list, which represents the contribution of this research. It was noted that two groups of safety climate factors mainly emerged from the study, as follows; 1) Management-related safety climate factors, and 2) Workers-related safety climate factors. Management-related safety climate factors are directly linked to the organization's management team. The way this team foresees safety has a direct impact on other employees with respect to safety perceptions. In fact, the majority of literature sources presented safety climate factors related to management more than that for workers. The management-related safety climate factors identified from the literature review process included the following: (1) management commitment to safety, (2) safety rules, and procedures, (3) supervision and guidance, (4) communication, (5) education and training, (6) work pressure and intensity, (7) safety resources, (8) supportive environment, (9) safety value and reward system, (10) management safety justice, (11) adequacy of procedures, (12) social security and health insurance, and (13) Workers' involvement. Here, 13 out of 18 safety climate factors were mainly related to the organization's management team and the remaining five identified safety climate factors were related to the workers. The five identified worker-related safety climate factors are (1) Worker's college influence, (2) Worker's attitude toward health and safety, (3) Appraisal of risk and hazard, (4) Competence, and (5) Workers' commitment to safety. Once again, this emphasizes the major role played by the management team with respect to safety in the organization. The top five mentioned safety climate factors were all related to the organization's management team. The least popular of these factors was mentioned in more than 10 journal articles. The factor management commitment to safety was mentioned in 20 different sources. Furthermore, the safety climate factor management commitment to safety was mentioned far more in the literature compared to workers' commitment to safety, with 20 and 2 sources, respectively. With respect to the five worker-related safety climate factors, worker's college influence was mentioned most, in nine journal articles. This indicates the important effect of workers on their colleges and that positive or negative safety actions will be transferred to workers from their colleges. The least 
mentioned safety climate factor in the literature was social security and health insurance, perhaps because this factor is generally considered as an essential feature of the workplace (except in the cases of illegal workers).

From Table 2, it can be determined that the influence of safety climate on workers is distributed across three levels of influence (see Figure 1). The first (and highest) level of influence comes from the organization's management team, due to the manner in which they prioritize safety, and the power they have with regard to implementing safety rules, procedures, and guidelines, on employees. This is followed by the influence of the workers on their colleges. According to the literate review, nine journal articles referenced worker college influence as a safety climate factor, and that positive or negative safety practices may be inherited by workers from their job colleges. The third level of safety climate influence is from the worker's background on safety. This depends on worker culture, nationality, number of dependents, language spoken, education, years of experience, and other personnel aspects that can affect perceptions of safety.
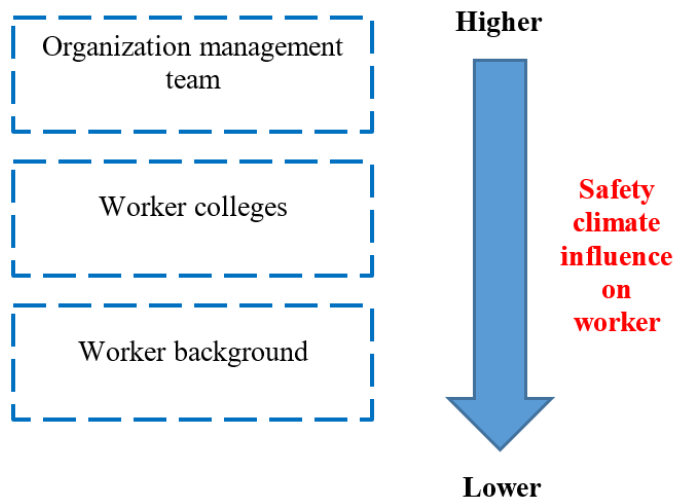

Figure 1. Safety climate influencing levels

\section{Conclusion and Future Work}

This study resulted in the identification of 18 factors that influences safety climate in the construction industry. In order to have a safe construction site with high safety performance levels, safety climate must be the utmost priority of any organization's management team. They represent the top of the pyramid of power and their decisions affect employees and work output. Furthermore, attention should be given to the influence of workers on their colleges in terms of positive or negative safety perceptions. Finally, construction workers must be encouraged to develop themselves to adopt safety climate good practice in their daily job activities and to promote good safety practices.

It will be interesting to conduct future research to explore, rank, and group the identified factors influencing safety climate in the construction industry, by using a questionnaire survey distributed among field professionals and workers. In addition, studying comparisons between different groups of industry professionals and their perspective on the identified factors influencing safety climate in the construction industry could yield interesting results. This will assist in providing a more holistic view on safety climate in the construction industry and add to the existing research available.

\section{REFERENCES}

[1] Nadhim, E., et al., Investigating the Relationships between Safety Climate and Safety Performance Indicators in Retrofitting Works. Construction Economics and Building, 2018. 18(2): p. 110-129.

[2] Wu, X., et al., Prospective safety performance evaluation on construction sites. Accident Analysis and Prevention, 2015. 78(May): p. 58-72.

[3] Melia', J., et al., Safety climate responses and the perceived risk of accidents in the construction industry. Safety Science, 2008. 46(6): p. 949-958.

[4] Zhu, C., et al., Occupational safety in China: Safety climate and its influence on safety-related behavior. China Information, 2010. 24(1): p. 27-59.

[5] Zhou, Q., D. Fang, and S. Mohamed, Safety Climate Improvement: Case Study in a Chinese Construction Company. Journal of Construction Engineering and Management, 2011. 137(1): p. 86-95.

[6] Brondino, M., M. Pasini, and S. Silva, Development and validation of an Integrated Organizational Safety Climate Questionnaire with multilevel confirmatory factor analysis. Quality \& Quantity 2013. 47(4): p. 2191-2223.

[7] Hon, C., A. Chan, and M. Yam, Determining Safety Climate Factors in the Repair, Maintenance, Minor Alteration, and Addition Sector of Hong Kong. Journal of Construction Engineering and Management, 2013. 139(5): p. 519-528.

[8] Cigularov, K., et al., Measurement equivalence of a safety climate measure among Hispanic and White Non-Hispanic construction workers. Safety Science, 2013. 54(April): p. 58-68.

[9] Chen, Y., B. McCabe, and D. Hyatt, Impact of individual resilience and safety climate on safety performance and psychological stress of construction workers: A case study of the Ontario construction industry. Journal of Safety Research, 2017. 61(June): p. 167-176.

[10] Andersen, L., et al., Social identity, safety climate and self-reported accidents among construction workers. Construction Management and Economics, 2017. 36(1): p. 22-31.

[11] Chan, A., et al., Investigating ethnic minorities' perceptions of safety climate in the construction industry. Journal of Safety Research, 2017. 63(December): p. 9-19.

[12] Huang, Y., et al., Safety Climate: How Can You Measure It and Why Does It Matter? Professional Safety, American Society of Safety Engineers 2017. 62(1): p. 28-35.

[13] Siu, O., D. Phillips, and T. Leung, Safety climate and safety performance among construction workers in Hong Kong The 
role of psychological strains as mediators. Accident Analysis and Prevention, 2004. 36(3): p. 359-366.

[14] Alruqi, W., M. Hallowell, and U. Techera, Safety climate dimensions and their relationship to construction safety performance: A meta-analytic review. Safety Science, 2018. 109(November): p. 165-173.

[15] Guo, B., T. Yiu, and V. González, Predicting safety behavior in the construction industry: Development and test of an integrative model. Safety Science, 2016. 84(April): p. 1-11.

[16] Boshoff, D., C. Krugell, and H. Heerden, Characteristics of the safety climate in teams with world-class safety performance on construction projects in South Africa. Acta Structilia, 2017. 24(1): p. 99-127.

[17] Pinion, C., et al., North American Engineering, Procurement, Fabrication and Construction Worker Safety Climate Perception Affected by Job Position. Safety, 2018. 4(2): p. $1-11$.

[18] Choudhry, R., D. Fang, and H. Lingard, Measuring Safety Climate of a Construction Company. Journal of Construction Engineering and Management, 2009. 135(9): p. 890-899.

[19] Lyu, S., et al., Relationships among Safety Climate, Safety Behavior, and Safety Outcomes for Ethnic Minority Construction Workers. International Journal of environmental Research and Public Health, 2018. 15(3): p. 484.

[20] Marín, L., et al., Perceptions of safety climate across construction personnel: Associations with injury rates. Safety Science, 2019. 118(October): p. 487-496.

[21] Mohamed, S., Safety Climate in Construction Site Environments. Journal of Construction Engineering and Management, 2002. 128(5): p. 375-384.

[22] Seo, H., et al., Analyzing safety behaviors of temporary construction workers using structural equation modeling. Safety Science, 2015. 77(August): p. 160-168.

[23] Fang, D., Y. Chen, and L. Wong, Safety Climate in
Construction Industry: A Case Study in Hong Kong. Journal of Construction Engineering and Management, 2006. 132(6): p. $573-584$.

[24] Wu, C., et al., Core Dimensions of the Construction Safety Climate for a Standardized Safety-Climate Measurement. Journal of Construction Engineering and Management, 2015. 141(8): p. 04015018-1.

[25] Zhou, Q., D. Fang, and X. Wang, A method to identify strategies for the improvement of human safety behavior by considering safety climate and personal experience. Safety Science, 2008. 46(10): p. 1406-1419.

[26] Li, Q., et al., Developing dimensions and key indicators for the safety climate within China's construction teams: A questionnaire survey on construction sites in Nanjing. Safety Science, 2017. 93(March): p. 266-276.

[27] Zahoor, H., et al., Modeling the Relationship between Safety Climate and Safety Performance in a Developing Construction Industry: A Cross-Cultural Validation Study. International Journal of environmental Research and Public Health 2017. 14(4): p. 351.

[28] Marín, L., et al., Associations between safety climate and safety management practices in the construction industry. American Journal of Industrial Medicine 2017. 60(6): p. 557-568.

[29] Patel, D. and K. Jha, Neural Network Model for the Prediction of Safe Work Behavior in Construction Projects. Journal of Construction Engineering and Management, 2015. 141(1): p. 04014066.

[30] Jiang, L., et al., Perceived colleagues' safety knowledge/behavior and safety performance: Safety climate as a moderator in a multilevel study. Accident Analysis and Prevention, 2010. 42(5): p. 1468-1476.

[31] Glendon, A. and D. Litherland, Safety cliamte factors, group differences and safety behaviour in road construction. Safety Science, 2001. 39(3): p. 157-188. 